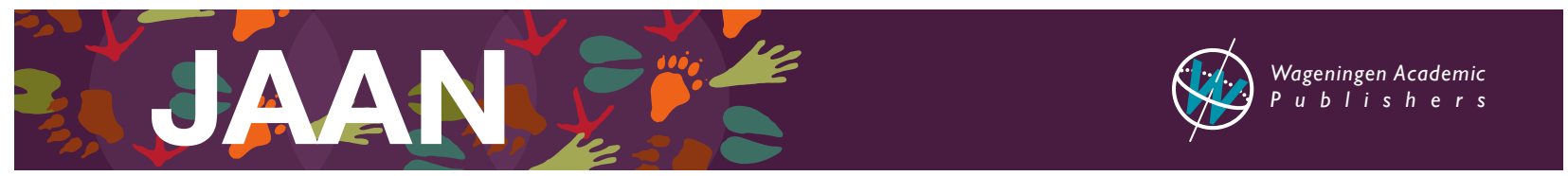

\title{
Reduction of cat voluntary feed intake in the short-term response to the sugar cane fibre supplementation
}

\author{
J. $\operatorname{Rogues}^{1^{*}}$, E. Mehinagic ${ }^{1}$, D. Lethuillier ${ }^{1}$, E. Bouvret ${ }^{1}$, M. Hervera ${ }^{2}$ and A. Lepoudere ${ }^{1}$ \\ ${ }^{1}$ Diana Pet Food, ZA du Gohélis, 56250 Elven, France; ${ }^{2}$ Expert Pet Nutrition, 44100 Nantes, France; \\ jrogues@diana-petfood.com
}

Received: 19 June 2020 / Accepted: 12 August 2020

(C) 2020 Rogues et al.

\section{RESEARCH ARTICLE COMPANION ANIMALS}

\begin{abstract}
Obesity is a well-known syndrome of excessive body fat in cats (Felis catus) that affects the health, welfare and lifespan of animals. Consequently, different diet strategies aiming to reduce voluntary feed intake in cats have been studied. One of these consists in reducing energy intake based on reduction of feed intake. Several clinical studies have demonstrated that dietary fibre inclusion in food reduced efficiently voluntary feed intake (VFI) in dogs. However, little clinical data is available regarding the impact of dietary fibre inclusion on cat's feeding behaviours and VFI. The aim of the current study was to test the performance of sugar cane fibre included at three different levels in extruded feline diets. The main purpose was to measure the impact of fibre inclusion on the cats' VFI, while maintaining palatability. Four feline diets were formulated with different inclusion levels of sugar cane fibre expressed on an as fed basis (0\% sugar cane fibre (control), 3.7\% of sugar cane fibre (SF3.7), 5.5\% of sugar cane fibre (SF5.5) and 7.3\% sugar cane fibre (SF7.3)). The VFI and palatability were evaluated in two different methods: a new method using 79 cats, called 'consumption kinetics' based on the dynamic measure of cat's daily consumptions in ad libitum conditions providing information about cat's feeding pattern, and the standard palatability two-bowl (versus) test using more than 30 cats. All foods had identical palatability performance, regardless of sugar cane fibre inclusion level, while the VFI of products containing 5.5\% and 7.3\% sugar cane fibre decreased significantly compared to the control diet. The level of supplementation of sugar cane fibre was efficient to reduce felines VFI without impairing food palatability level, and may be a useful ingredient to add to feline diets to improve the success of the weight management programs.
\end{abstract}

Keywords: feline, kinetics of consumption, obesity, weight loss

\section{Introduction}

Obesity is a well-known disease affecting feline health and welfare (German, 2006). In developed countries, obesity has been identified as one of the most prevalent clinical conditions occurring in indoor cats (Cave et al., 2012; Chandler et al., 2017; Corbee, 2014; Courcier et al., 2010, 2012; German, 2006). Cat obesity has increased from a range of $6-12.5 \%$ in the 1970 s to $63 \%$ in occidental countries in recent reports (Cave et al., 2012; Colliard et al., 2009; Corbee, 2014; Rowe et al., 2015; Tarkosova et al., 2016). Overweight cats are at increased risk of developing diabetes mellitus, neoplasia, skin diseases, oral cavity diseases and urinary diseases (Laflamme, 2012; Lund et al., 2005). Moreover, an excess of adiposity increases the risk of respiratory diseases (Bach et al., 2007) and causes metabolic problems (German et al., 2010a; Tvarijonaviciute et al., 2012).

Energy intake restriction is effective to achieve weight loss in obese cats (Butterwick and Markwell, 1996; German et al., 2008), and limited energy intake must be implemented in weight control strategies. Low energy density diets have been suggested to improve pet owner's compliance, 
limit hunger signs and begging behaviours in dogs and cats on weight loss therapy (German, 2016). Common dietary strategies, in order to reduce energy density in pet diets, include increasing the volume of food by producing bigger, aerated kibbles (Serisier et al., 2014), increasing water content (Alexander et al., 2014), or to increase the inclusion of dietary fibre from non-digestible carbohydratebased plant materials (De Godoy et al., 2013; German et al., 2010b; Hours et al., 2016). Although dietary fibre is not a required nutrient in feline nutrition, the inclusion of optimal amounts of indigestible material in the diet allows a proper intestinal peristalsis and gut physiology (Kienzle et al., 1991). In fact, the natural diet of cats consists of whole preys that include indigestible glycoprotein rich materials, such as bones, tendons, cartilages, skins, hair and feathers (Verbrugghe and Hesta, 2017). Most of those tissues are not or are incompletely digested and would therefore have a physiological function as fibre. They pass through the intestinal system as bulk without being assimilated; and may or may not be fermented, improving faecal quality and gut health, as suggested in wild felids (Depauw et al., 2013). In feline diets, fibre sources have been included to promote faecal formation and quality (Prola et al., 2006), to prevent hairball formation (Beynen et al., 2011; Loureiro et al., 2014) and to limit energy content, by reducing nutrient digestibility (Earle et al., 1998; Fekete et al., 2004; Prola et al.,2006).

Moreover, several clinical studies have demonstrated that dietary fibre inclusion in various proportions reduced voluntary feed intake (VFI) efficiently in humans and dogs (Dobenecker and Kienzle, 1998; German et al., 2010b; Gerstein et al., 2004; Howarth et al., 2001; Weber et al., 2007). Those studies suggested that fibres might have an effect improving sensation of fullness and global intake. However, little clinical data is available regarding the impact of dietary fibre inclusion on cat VFI. Most of the existing studies have dealt with commercial products combining several nutritional strategies in composition, such as low fat, high protein or high fibre content (Cline et al., 2012; Hours et al., 2016).

Sugar cane fibre is highly insoluble and poorly fermentable (Fischer et al., 2012; Musco, 2014), and may allow a higher inclusion rate while avoiding soft faecal matter. The benefits of sugar cane fibre have been demonstrated by Fischer et al. (2012) on glucose metabolism in overweight cats, including the reduction of postprandial glucose concentrations.

Effects of fibre content in feline diets on VFI lacks any clear conclusion, and the main limitations of studies are the difficulty of measure subjective feelings of fullness and preference from cats and the lack a of a consensual methodology to test such an effect. The aim of the current study was to test the impact of sugar cane fibre inclusion in cat food using two methods, the VFI and palatability measurement. Sugar cane fibre was introduced at three different levels in kibble (3.7, 5.5 and 7.3\%) compared to an unsupplemented control, with the hypothesis that inclusion of fibre in feline weight management diets may induce the decrease of VFI without decreasing sensory appreciation of food. In order to measure both, the sensory appreciation of food and cat's eating behaviour, two methods were employed: a 'versus' or two-bowl test which consist in serving two diets simultaneously to cats and measuring their preferences, and analysis of cat's kinetics of consumption in a short-term evaluation measuring the macrostructure and microstructure of cat feeding behaviours during the first 20 hours exposure to the pet food.

\section{Materials and methods}

\section{Ethical statements}

The study was undertaken in April and May 2018 by Diana Pet Food's expert panel for pet palatability measurement (Panelis Ltd, Elven, France). This facility is in compliance with the rules of the French Ministry of Agriculture. The participating cats were in living conditions similar to those found in an 'in-home' environment, and benefitted every day from a varied well-being programme. Only behavioural data and VFI were monitored, so no special permission for the protocol was required by the French Authorities, as the research protocol was not subject to the EU Directive 2010/63/EU. Since all studies were undertaken in research colony animals from the institution of the authors, no informed consent was required from owners.

\section{Fibre}

Sugar cane fibre was obtained from Vivae (Diana Pet Food, Elven, France) and the Dilumix partnership (Dilumix Industrial Ltda., Leme, Brazil). Sugar cane fibre was derived from Saccharum officinarum, a plant listed in the GBIF (Global Biodiversity Information Facility; Specie description Sp. Pl. 1: 54 (1753)). It is mainly composed of insoluble fibre ( $88.6 \%$ on a fed basis). It has high levels of neutral detergent fibre (NDF) consisting of cellulose, hemicelluloses and lignin (86.1\% as fed), acid detergent fibre (ADF) consisting of cellulose and lignin (55.8\%) and acid detergent lignin (8.7\%); indicating a significant proportion of poorly fermentable hemicelluloses ( $30 \%$ by difference between NDF and ADF). The characteristics of the sugar cane fibre are presented in Table 1.

\section{Diets}

Four experimental extruded diets were produced. All diets were formulated according to FEDIAF recommendations for adult cats (FEDIAF, 2019). The diets had the same coatings, $6 \%$ poultry fat and $2 \%$ pork-based palatability enhancer. All diets contained $4 \%$ sugar beet pulp, as a common source 
Table 1. Characterisation of the sugar cane fibre as fed basis used in the study.

$\begin{array}{lc}\text { Chemical composition (\%) } & \begin{array}{l}\text { Sugar cane fibre } \\ \text { (mean } \pm \text { SEM of } 7 \text { batches) }\end{array} \\ \text { Moisture } & 2.7 \pm 1.3 \\ \text { Protein } & 2.7 \pm 0.3 \\ \text { Fat } & 0.7 \pm 0.1 \\ \text { Ash } & 3.0 \pm 1.0 \\ \text { Total dietary fibre (TDF) } & 87.1 \pm 1.7 \\ \text { Crude fibre (cellulose) } & 46.4 \pm 2.9 \\ \text { Nitrogen free extract (NFE) } & 45.5 \pm 1.6 \\ \quad \text { (calculated) } & 86.1 \pm 1.6 \\ \text { Neutral detergent fibre (NDF) } & 55.8 \pm 1.6 \\ \text { Acid detergent fibre (ADF) } & 8.7 \pm 0.4 \\ \text { Acid detergent lignin (ADL) } & 0.9 \\ \text { Soluble fibre } & \\ \text { Insoluble fibre }^{1} & 88.6 \\ \text { 1 }^{1} \text { Analyse done on one batch } & \end{array}$

${ }^{1}$ Analyse done on one batch.

of fibre. The three fibre-enriched diets included increasing levels of sugar cane fibre: either 3.7\% (SF3.7), 5.5\% (SF5.5) or $7.3 \%$ of added sugar cane fibre (SF7.3). Sugar cane fibre replaced rice flour in the formula and a control diet contained no sugar cane fibre. Diet composition is shown in Table 2. The diets were formulated to be equivalent in energy, protein and fat contents. The quantity of sugar cane fibre added was lower than $8 \%$ to preserve theoretical food palatability, which has a specific threshold, identified from previous internal studies (data not shown).
The chemical composition of the diets and the sugar cane fibre were analysed according to the European Union Commission regulation (EC) no. 152/2009 regarding crude protein, ash, acid hydrolysed fat extract, crude fibre and moisture content, and nitrogen free extract was calculated as the difference between dry matter and the sum of ash, crude protein, crude fat and crude fibre. Total dietary fibre was analysed by AOAC method 985.29 (Prosky et al., 1992). For diet composition, metabolisable energy was estimated according to modified Atwater factors (National Research Council, 1986). For sugar cane fibre, methods for analysing fibre composition (NDF, ADF, acid detergent lignin) were derived from the sequential method described by Van Soest (AFNOR NF V18-122, 1997), and soluble fibre and insoluble fibre were analysed according to AOAC method 991.43.

\section{Processing parameters}

All diets were mixed and ground in a hammer mill before being extruded and kibbled under adjusted processing conditions. The manufacturing process was controlled to obtain kibble density between 340 and 360 $\mathrm{g} / \mathrm{l}$. Preconditioner and extruder temperature were kept similar for all the diets. Due to the fibre inclusion in the diet formulation and its impact on mix density, dry mix flow was adjusted to obtain a similar kibble apparent density. After extrusion, the kibbles were dried in a forced-air dryer (128 to $130{ }^{\circ} \mathrm{C}$ ) and coated with fat and palatability enhancers.

Table 2. Ingredient and chemical composition of the experimental diets for cats with different sugar cane fibre inclusion levels.

\begin{tabular}{|c|c|c|c|c|}
\hline & \multicolumn{4}{|c|}{ Experimental diets ${ }^{1}$} \\
\hline & Control & SF3.7 & SF5.5 & SF7.3 \\
\hline \multicolumn{5}{|l|}{ Chemical composition (\%) } \\
\hline Moisture & 7.3 & 4.8 & 5.6 & 5.3 \\
\hline Protein & 32.5 & 32.7 & 33.8 & 32.8 \\
\hline Fat & 11.3 & 11.3 & 11.1 & 10.9 \\
\hline Ash & 6.2 & 6.3 & 6.4 & 6.5 \\
\hline Total dietary fibre & 8.2 & 11.7 & 13.2 & 14.8 \\
\hline Crude fibre & 2.4 & 4.4 & 5.0 & 6.1 \\
\hline Nitrogen free extract (NFE) & 40.3 & 40.5 & 38.1 & 38.4 \\
\hline \multicolumn{5}{|l|}{ Ingredient composition (\%) } \\
\hline Sugar cane fibre & 0.0 & 3.7 & 5.5 & 7.3 \\
\hline Rice flour & 13.8 & 10.1 & 8.3 & 6.4 \\
\hline Maize & 8 & 8 & 8 & 8 \\
\hline Broken rice & 12.5 & 12.5 & 12.5 & 12.5 \\
\hline Corn gluten meal & 6.9 & 6.9 & 6.9 & 6.9 \\
\hline Corn meal & 9.2 & 9.2 & 9.2 & 9.2 \\
\hline Beet pulp & 4.4 & 4.4 & 4.4 & 4.4 \\
\hline Beef greaves & 13.7 & 13.7 & 13.7 & 13.7 \\
\hline Poultry by product meal & 13.3 & 13.3 & 13.3 & 13.3 \\
\hline Fish meal & 3.2 & 3.2 & 3.2 & 3.2 \\
\hline Yeast & 3.5 & 3.5 & 3.5 & 3.5 \\
\hline Minor ingredients (antioxidant, taurine, vitamins, minerals) & 3.6 & 3.6 & 3.6 & 3.6 \\
\hline Poultry fat & 6.0 & 6.0 & 6.0 & 6.0 \\
\hline Powdered pork based palatant & 2.0 & 2.0 & 2.0 & 2.0 \\
\hline
\end{tabular}

${ }^{1}$ Control $=$ without sugar cane fibre; SF3.7 $=3.7 \%$ of added sugar cane fibre; SF5.5 $=5.5 \%$ of added sugar cane fibre; SF7.3 $=7.3 \%$ of added sugar cane fibre . 
To determine physical characteristics of the kibbles, a cutting test was performed with a texturometer (LLOYD instruments, TA plus Ametek, West Sussex, UK) and apparent density was determined. The processing parameters and kibble physical characterisation are presented in Table 3.

\section{Palatability two-bowl method}

The palatability trial involved 38 healthy adult domestic cats and was conducted in May 2018. The tested cats had an average weight of $3.87 \pm 1.4 \mathrm{~kg}$ (range from 2.2 to 8.3 $\mathrm{kg}$ ), were $3.9 \pm 2.8$ years old (range from 1 to 12 years) and comprised 22 intact females, one neutered female, one intact male and 14 neutered males. The cats were split in three groups, and housed in three separate cattery living areas for several months before the beginning of the study. Thirty cats had an ideal BCS (4-5/9), five cats were overweight (BCS 6 or 8/9) and BCS was missing for three of them.

All the cats regularly participated in sensory studies. For each test, two diets were served, side-by-side in identical bowls, with the same quantity of food per bowl (110 to 120 $\mathrm{g}$ of diet per bowl). The living rooms were equipped with automatic feeding stations corresponding to the number of cats with free access for all cats in all stations between the hours of 16.30 to 07.30 the following day to ensure that food was available during the known times of peak consumption within the colony (during the evening or early morning) which fits with the cats eating habits. Water was freely available for consumption throughout the study. Each cat was equipped with a microchip and the individual food

Table 3. Extrusion parameters of the cat experimental diets with different sugar cane fibre inclusion levels.

\begin{tabular}{|c|c|c|c|c|}
\hline & \multicolumn{4}{|c|}{ Experimental diets ${ }^{1}$} \\
\hline & Control & SF3.7 & SF5.5 & SF7.3 \\
\hline \multicolumn{5}{|l|}{ Process parameters } \\
\hline Dry mix flow (kg/h) & 412.1 & 386.9 & 366.9 & 370.1 \\
\hline Preconditioner speed (rpm) & 100 & 100 & 100 & 100 \\
\hline Extruder screw speed (rpm) & 630 & 630 & 630 & 630 \\
\hline Extruder die $\mathrm{T}^{\circ}\left({ }^{\circ} \mathrm{C}\right)$ & 97 & 95 & 98 & \\
\hline Hole number and diameter (mm) & $8 \times 7$ & $8 \times 7$ & $8 \times 7$ & $8 \times 7$ \\
\hline Output flow $(\mathrm{kg} / \mathrm{h})$ & 475 & 450 & 433 & 438 \\
\hline Output density (g/l) & 350 & 350 & 365 & 365 \\
\hline Dryer temperature set point $\left({ }^{\circ} \mathrm{C}\right)$ & 129 & 130 & 129 & 128 \\
\hline \multicolumn{5}{|l|}{ Kibble characterisation } \\
\hline $\begin{array}{l}\text { Coated kibble apparent density } \\
(\mathrm{g} / \mathrm{l})\end{array}$ & 352 & 350 & 345 & 361 \\
\hline $\begin{array}{l}\text { Starch gelatinisation degree of } \\
\text { coated kibble }(\%)\end{array}$ & 88.74 & 85.26 & 85.76 & 84.47 \\
\hline Rigidity (N/mm) & 59.42 & 63.98 & 52.93 & 48.45 \\
\hline $\begin{array}{l}\text { Deformation to the maximal } \\
\text { cutting force }(\mathrm{mm})\end{array}$ & 0.56 & 0.53 & 0.69 & 0.85 \\
\hline Maximal cutting force $(\mathrm{N})$ & 33.07 & 33.6 & 36.6 & 41.04 \\
\hline
\end{tabular}

${ }^{1}$ Control $=$ without sugar cane fibre; SF3.7 $=3.7 \%$ of added sugar cane fibre; SF5.5 $=5.5 \%$ of added sugar cane fibre; SF7.3 $=7.3 \%$ of added sugar cane fibre. intake (in grams) was recorded daily using electronic weight scales (M-Tronic, Paris, France, accurate to within $0.5 \mathrm{~g}$ ).

Three paired comparison tests were done at three different dates in May 2018, testing the control diet vs each of the fibre enriched diets, whereby control versus SF3.7 $(n=31)$, control versus SF5.5 $(n=30)$ and control versus SF7.3 $(n=33)$. Once the test was completed, cumulative feed intake per cat was calculated for each diet, as well as the food intake ratio $(\mathrm{A} /(\mathrm{A}+\mathrm{B}))$.

\section{Consumption kinetics method}

The consumption kinetics method involved 79 healthy adult cats housed in two catteries. The tested cats had an average weight of $3.76 \pm 0.9 \mathrm{~kg}$ (range from 2.2 to 6.3 $\mathrm{kg}$ ), were $3.4 \pm 2.5$ years old (range from 1 to 12 years) and contained 34 intact females, four neutered females, one intact male and 40 neutered males. The cats were split into eight groups, and housed in eight separate rooms (with a maximum of 10 cats per room) for several months before the beginning of the study. Sixty-one cats had an ideal body condition score (BCS 4-5/9), one was underweight cat (BCS 3/9), 13 overweight cats (BCS 6-7/9) and BCS was missing for four of them.

Cats were group-housed in closed indoor areas $\left(13 \mathrm{~m}^{2}\right)$ and outdoor runs $\left(13 \mathrm{~m}^{2}\right)$, with a maximum of 10 cats per run. Cats had free access to the outdoor runs at all times. Cats were fed using automated feeding stations (see below). The ambient temperature of living rooms was maintained at $21 \pm 3{ }^{\circ} \mathrm{C}$. All cats had exercise and play sessions with caregivers ( $2 \mathrm{~h}$ per day). All the animals remained healthy during the study and, after this protocol, they continued to perform other studies at Panelis.

During each session, the test food was available to the cats during a 20-hour period from 11:30 am to 7:30 am the following day. A specific feeding system was used, as described by Larose et al. (2007) and Tobie et al. (2015). Each room was equipped with two feeding stations allowing only one cat to enter the feeding station at a time. In that way, cats had freedom of movement and could behave naturally, as they were not exposed to feeding competition with other cats. The food was placed into two stainless steel bowls at the centre of the feeding area. A set of scales was placed under each bowl to measure the consumption per cat for each feeding event. Two feeding stations per room were sufficient to allow easy access to food for all cats in the group. All the feeding stations were connected to a computer system (Dell Inc., Round Rock, TX, USA) which recorded various data about the cats' feeding, including time, duration and food consumption. In order to link specific behaviour to a specific diet, only one diet per session was tested. 
The products were presented to the cats following a $4 \times 4$ Williams Latin square design. Each subgroup received a different sequence of the four products to avoid the 'previous product' effect and the 'order' effect. This randomisation prevented bias of any 'novelty effect'. The two feeding stations contained $1 \mathrm{~kg}$ of kibbles each in order to allow ad libitum access for the 10 cats from each room in the 20-hour period. The microstructure of cats' eating behaviours was evaluated by the following criteria: Cat VFI at the end of the 20 hour-testing period (expressed in $g$ and kcal); change of energy intake was calculated between each product and the control product and transformed into a percentage; maximum food intake reached for one feeding event throughout the test was measured; number of feeding events measured with food intake per cat during a 20 hour period; number of animals performing at least one feeding event during the first 30 minutes monitored; number of animals with at least one low consumption feeding event (less than 2 grams) in the 20 hour feeding period recorded; feed intake at each feeding event and especially at the first feeding event measured and temporal analysis of cumulative food intake per hour and per cat recorded ( $\mathrm{g}$ in relation to h). A 'consumption event' was considered only if the cat ate at least $0.5 \mathrm{~g}$ of food.

\section{Data handling and statistical analysis}

The sample sizes for the two studies were not determined according to a power sample analysis calculation. Instead, this number was based upon the classical number of previous trials assessing the VFI of cats and the palatability assessment. For the study recording cats' consumption kinetics, all feeding events and individual VFI at each feeding event were recorded, while for the palatability study, the outcome was the amount of each diet consumed at the end of the test.

For the palatability study, data were analysed using a paired t-test on the difference between the consumption ratio of the tested products. Each cat was used to test each pair of products, so the unit of analysis for the Student t-test was the cat. Differences among the feeds were declared as statistically significant when the $P$-value was lower than $5 \%$.

Data regarding all the criteria listed above for each cat and each product was obtained, processed and analysed using SAS enterprise guide 7.1 (SAS Institute Inc., Cary, NC, USA). A linear mixed model was computed with the variable 'cat' as a random effect and the diet as the fixed effect for the quantitative variables (PROC MIXED) and a logistic regression with the variable 'cat' as a random effect and the diet as the fixed effect for the binary variables (PROC GLIMMIX). These analyses were done at each time point for the criteria measured over the time period. The unit of analysis for all the models was the cat, with inclusion of the individual variability in the random term of each analysis. Tukey HSD was used for post-hoc tests when comparing the products (Tukey, 1949). Differences among least square means, with a $P$-value lower than $5 \%$, were accepted as statistically significant.

\section{Results}

\section{Palatability two-bowl method}

The two-bowl palatability results are displayed in Figure 1. According to the Student t-test, feed intake ratios for the SF supplemented diets were not significantly different to the control, indicating similar palatability among all diets.

\section{Consumption kinetics}

All the results of the consumption kinetics criteria are shown in Table 4. The products did not differ in terms of energy density, with variation between products being less than $5 \%$.

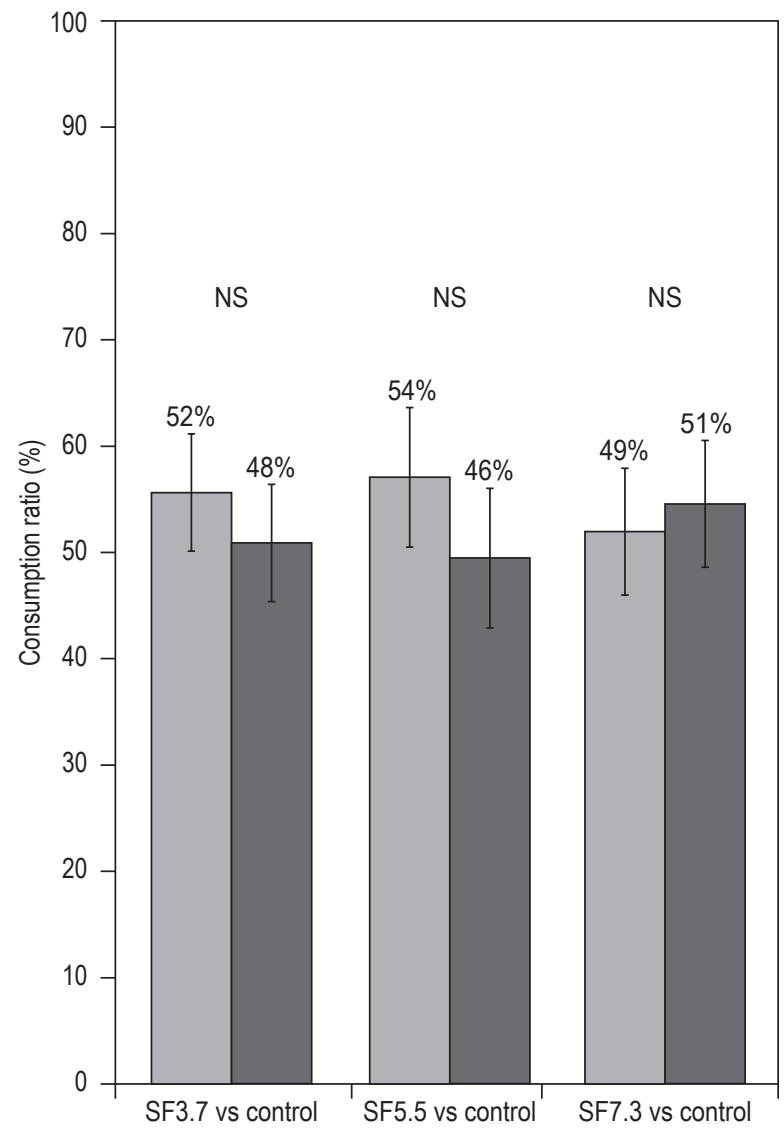

Figure 1. Mean consumption ratio and standard error of mean for the three paired palatability tests. Control = no sugar cane fibre added; SF3.7 $=3.7 \%$ of added sugar cane fibre; SF5.5 $=5.5 \%$ of added sugar cane fibre; SF7.3 $=7.3 \%$ of added sugar cane fibre. The total number of available data per trial was: 31 for control vs SF3.7, 30 for control vs SF5.5 and 33 for control vs SF7.3. NS: $P>0.05$; ${ }^{*} P \leq 0.05$; ${ }^{* *} P \leq 0.01$; ** $P \leq 0.001$. 
Table 4. Results of consumption kinetics. Adjusted means and standard errors of mean per product. ${ }^{1,2}$

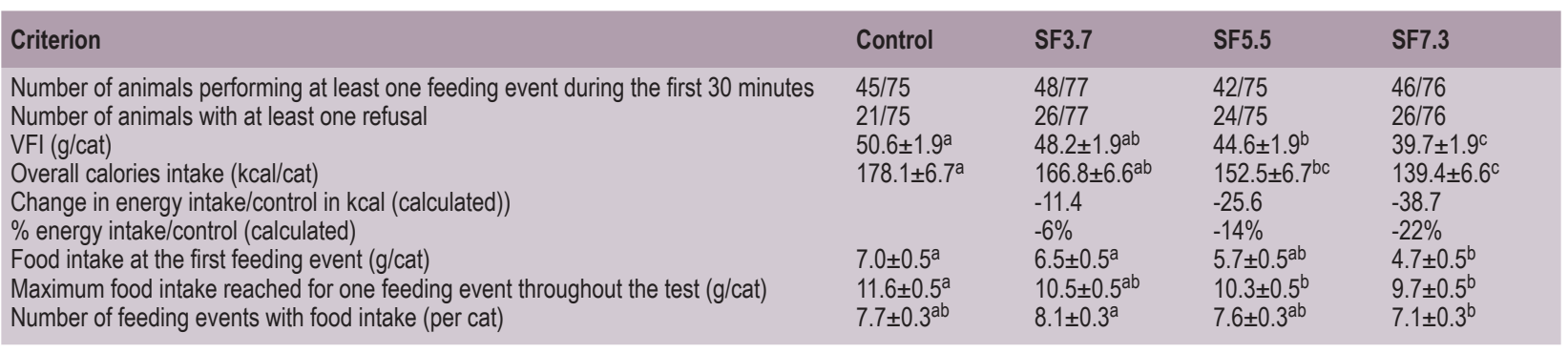

${ }^{1}$ Control = no sugar cane fibre added $(n=75)$; SF3.7 = 3.7\% of added sugar cane fibre $(n=77)$; SF5.5 = 5.5\% of added sugar cane fibre ( $\left.n=75\right)$; SF7.3 = 7.3\% of added sugar cane fibre $(n=76)$.

2 Different letters in a row indicate significant differences $(P<0.05)$ between the products based on Tukey HSD post-hoc test. The absence of letters in a row indicates that all the products were not significantly different.

The percentage of animals performing at least one feeding event during the first 30 minutes was not significantly different between diets. The acceptability of all of the diets was equivalent, as measured by the number of animals with at least one low consumption feeding event, which were not significant among the diets.

The VFI was significantly reduced with the SF5.5 and SF7.3 diets, which were $44.6 \pm 1.9 \mathrm{~g}$ and $39.7 \pm 1.9 \mathrm{~g}$, respectively, compared to the control diet $(50.6 \pm 1.9 \mathrm{~g})$. The SF3.7 $(48.2 \pm 1.9 \mathrm{~g})$ diet did not significantly reduce the VFI compared to control diet.

For total calorie intake at the end of the test, energy consumption was reduced by $6 \%$ for SF3.7, 14\% for SF5.5 and $22 \%$ for SF7.3, compared to the control diet. These differences were already observed in the first feeding trial, where there was a significantly lower intake measured for SF7.3 (4.7 $\pm 0.5 \mathrm{~g})$ compared to the control diet $(7.0 \pm 0.5 \mathrm{~g})$.

The maximum food intake per feeding event showed a difference between SF7.3 and the control diet, with values of $9.7 \pm 0.5 \mathrm{~g}$ and $11.6 \pm 0.5 \mathrm{~g}$, respectively. This difference occurred for SF5.5, which had a significantly lower value than the control diet $(10.3 \pm 0.5 \mathrm{~g})$. The effect of SF3.7 $(10.5 \pm 0.5 \mathrm{~g})$ was intermediate and not significantly different from all the other diets.

There were a number of feeding events where intake differed significantly between the four products. i.e. the SF7.3 diet (7.1 \pm 0.3$)$ showed a significantly lower number of feeding events than SF3.7 (8.1 \pm 0.3$)$, which were strong trends when compared to the control diet $(7.7 \pm 0.3 ; P=0.07)$. Figure 2 represents the cumulative VFI per hour and per experimental diet.

Temporal analysis of consumption showed a persistently lower cumulative intake for the SF7.3 diet compared to the control diet. This result was significant after four hours of the feeding test $\left(P<0.05\right.$ after the $4^{\text {th }}$ hour of test and
$P<0.001$ after the $5^{\text {th }}$ hour of test). The decrease in intake for SF5.5 was observed after the $4^{\text {th }}$ hour of the test, but was to lesser extent than seen with SF7.3 diet. The reduction in overall food intake compared to control diet was $13 \%$ for SF5.5 and of 22\% for SF7.3. The SF3.7 diet showed a similar intake pattern throughout the test to the control diet. Therefore, overall SF3.7 food intake was not statistically different from the control, leading to a $6 \%$ energy intake reduction.

\section{Discussion}

Palatability plays an important role early in satiation, directing food choice behaviour and amounts eaten (McCrickerd and Forde, 2016). Palatability can be divided into liking (hedonic value) and wanting (motivation to eat) behaviour, as described by Mela (2006). In this study, all diets were equivalent in palatability and the cats showed no preferences between the control and fibre-enriched diets. The macrostructure of feeding behaviour in wild and feral animals is based on quite simple choices such as 'when', 'what' and 'how much to eat' (Day et al., 1998). However, the microstructure of feeding behaviour can involve a wide diversity of behavioural elements. Cat feeding behaviour is not continuous, but usually occurs in multiple bouts. Kane et al. (1981) found that cats eat approximately 16 meals per day and consume a mean of $4.8 \mathrm{~g}$ of dry matter per meal. Feeding can therefore be described in greater detail by taking account its microstructure, for example, duration of feeding, frequency of bouts, and local rate of eating. The results obtained in the current consumption kinetics study were not influenced by any sensory properties of the diets. The decrease in VFI, and, consequently, in energy intake, measured for products enriched in sugar cane fibre (at 5.5\% and $7.3 \%$ inclusion levels), can be attributed solely to diet composition effects and, thus, to fibre inclusion.

During the 20-hour period of consumption, a reduction in cat VFI was observed when at least 5.5\% sugar cane fibre was included in the diet. This threshold may be explained 


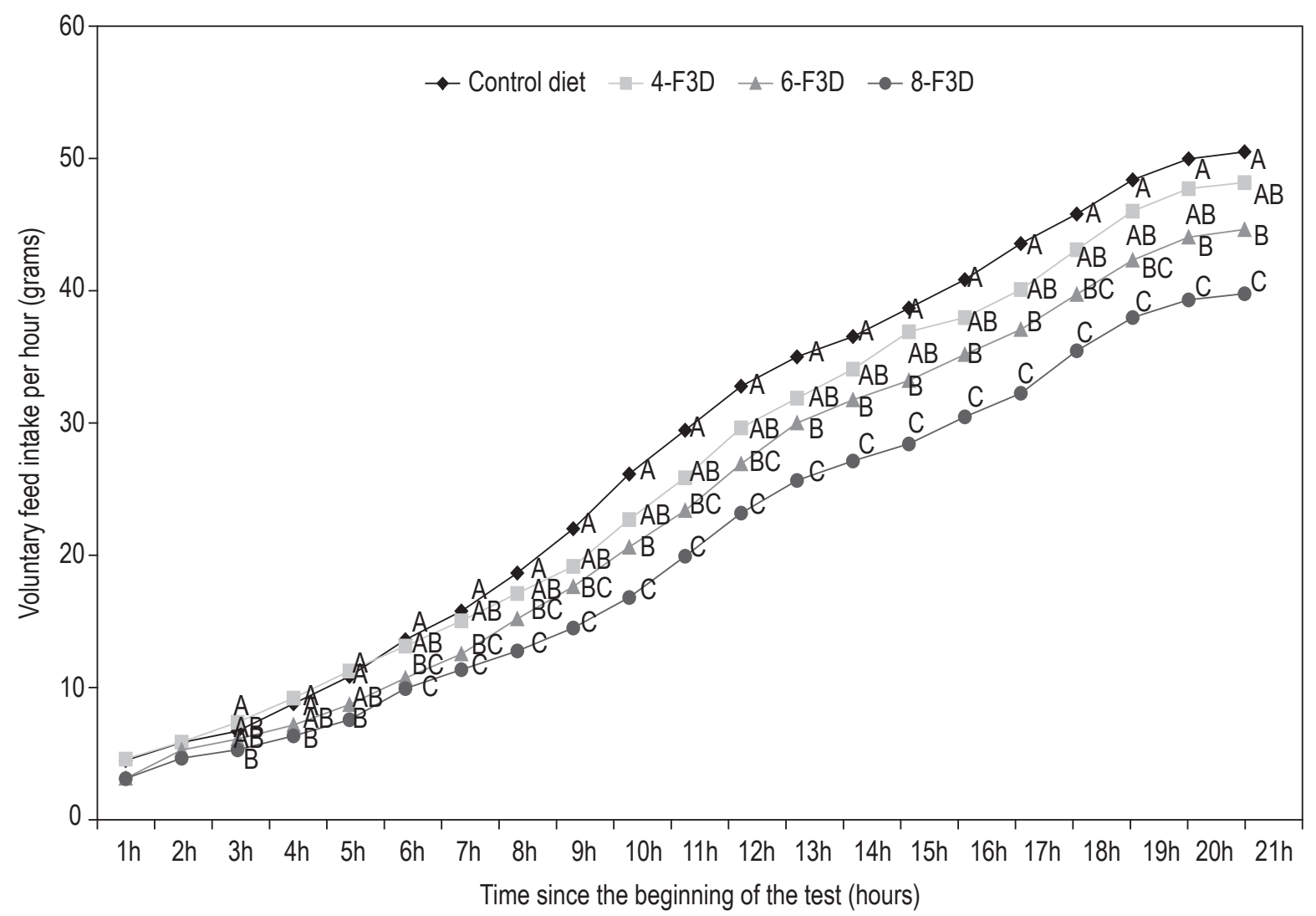

Figure 2. Temporal analysis of the kinetics of consumption with the cumulative voluntary feed intake per hour per cat for the 4 diets. Means not sharing a letter indicate significant differences between products based on Tukey HSD post-hoc test $(P<0.05)$. Control $=$ no sugar cane fibre added; SF3.7 $=3.7 \%$ of added sugar cane fibre; SF5.5 = 5.5\% of added sugar cane fibre; SF7.3 = 7.3 $\%$ of added sugar cane fibre.

as a minimal level of fibre intake is required to trigger a 'fullness' sensation for the cat. This was supported by the reduction of maximal intake per feeding event observed in cats for SF5.5 and SF7.3 diets. When testing the effect of sugar cane fibre supplementation on inter-meal intake regulation throughout all feeding events, as evaluated by the interval between two feeding events, the threshold was increased, as only the SF7.3 significantly reduced the number of feeding events and, thus, increased the interval between meals. Under the current experimental conditions, $1 \%$ (as fed) of added total dietary fibre (TDF) provided by sugar cane, replacing $1 \%$ of a digestible carbohydrate source in the diet, enabled a $5 \%$ daily energy intake reduction, compared to the control diet. However, such effects on cat VFI was not seen in a 42-day longitudinal study by Loureiro et al. (2017), when they tested 10 or $20 \%$ sugar cane fibre inclusion in diets on an as fed basis. The authors concluded that there was no energy intake reduction under their trial conditions, and they hypothesised that cats were able to adjust their dry matter intake to achieve similar energy intake. This last hypothesis was at odds with results obtained by Prola et al. (2006), who showed a reduction of energy intake with diets diluted by fibre addition.
The regulation of VFI is related by a complex system influenced by dietary energy density and nutrient composition. It involves different physiological mechanisms triggered by nervous and sensory stimuli, neurotransmitters and hormones (Schwartz et al., 2000). Suggested mechanisms of VFI reduction by insoluble fibres include stomach fullness, delayed gastric emptying and intestinal filling. Stomach fullness is related to the water holding capacity of the fibre, which is determined by its particle size, $\mathrm{pH}$ or ionic strength. This may result in the stimulation of anorexogenic hormone release (Hawthorne and Butterwick, 1998; Musco, 2014; Weber et al., 2007). Wang et al. (2012) demonstrated an effect of sugar cane fibre supplementation in mice fed high fat diets on circulating glucagon-like peptid-1 levels, a gastrointestinal hormone, which is implicated in the regulation of gut motility, appetite, VFI and glucagon secretion.

Another hypothesis for the effect of sugar cane fibre on cat VFI could be related to the high proportion of hemicellulose and lignin of the sugar cane fibre (Veloso et al., 2014). Lignin can reduce digestive enzyme activity (Hansen, 1986) and bind bile acids (Kay, 1982), which leads to reduced fat absorption (Eastwood et al., 1986). Loureiro et al. (2017) 
observed decreased fat digestibility when $10 \%$ sugar cane fibre was supplemented in felid diets, which was not the case with $10 \%$ cellulose supplementation. This suggested that the insoluble characteristic of fibre was not sufficient for predicting physiological effects of the feed. The presence of fat in the distal part of the small intestine increases the release of anorexogenic hormones, cholecystokinin and peptide YY, resulting in a significant reduction of food intake (the 'ileal brake' phenomenon) in healthy humans (Van Avesaat et al., 2015). A higher presence of fat in the distal part of the small intestine, caused by reduced fat digestibility resulting from increased dietary lignin, may support the reduction of VFI with sugar cane fibre inclusion, as reported in the present study. Finally, Fischer et al. (2012) tested the influence of sugar cane fibre in feline weight management formulations ( $>24 \%$ TDF). They specifically evaluated the effect of sugar cane fibre on nutrient digestibility, gut health and glucose postprandial responses, in comparison with sugar beet pulp (a partly soluble and fermentable fibre) and wheat bran (an insoluble fibre). Interestingly, sugar cane fibre inclusion in the diet decreased mean glucose concentrations, whereby the glucose area under the curve was reduced by $24 \%$ in comparison with the other fibreenriched diets. Fischer et al. (2012) hypothesised that the sugar cane fibre effect was either a consequence of reduced energy digestibility or poorer propionate formation and absorption, due to low fermentability, where the propionate was possibly converted in glucose by the liver. They concluded that sugar cane fibre was a promising ingredient for formulating obesity diets for cats.

Dietary fibre inclusion in cat food reduces nutrient digestibility, according previous studies (Fekete et al., 2001; Fischer et al., 2012; Harper and Siever-Kelly, 1997; Kienzle et al., 2001; Loureiro et al., 2017; Prola et al., 2006). The suggested main causes of nutrient digestibility impairment include gastrointestinal transit time (Burrows and Merritt, 1983), alteration in mixing and convection, digestion, the thickness of unstirred layer, bulk viscosity, $\mathrm{pH}$ changes (Vinik and Jenkins, 1988) as well as an influence on pancreatic secretions (Stock-Damgé et al., 1983). The extent of the effect of fibre on nutrient digestibility differs depending on the fibre source. In a study with 32 adult cats, sugar cane fibre inclusion at $10 \%$ in the diet did not alter retention time, but cellulose addition at same level significantly reduced retention during a 42 day period (Loureiro et al., 2017). Authors suggested that this might be related to the higher water-holding capability of sugar cane and its larger fibre size.

Nutrient digestibility reduction, induced by fibre inclusion in diets, may impact nutrient availability if it is not considered during formulation. The FEDIAF minimum recommended nutrient levels are deemed adequate for pet foods with nutrient digestibility of dry matter $\geq 70 \%$ and crude protein $\geq 80 \%$ and average bioavailability (FEDIAF,
2019). For feeds with lower digestibility values, increased protein and amino acid food content should be included. This is especially important for essential nutrients such as taurine, where losses may be increased by higher dietary fibre (Kim et al., 1995; Stratton-Phelps et al., 2002).

In the study where adult cats were fed a diet supplemented with $10 \%$ sugar cane fibre (i.e. higher than levels used in the present study) digestibility of dry matter was $73.1 \%$ and crude protein digestibility was $81.9 \%$ (Loureiro et al., 2017). In a complete cat food formulated to meet FEDIAF recommended nutrient levels, supplementation with sugar cane levels of up to $10 \%$ (TDF contents up to $20.8 \%$, as fed) is not expected to significantly affect protein and amino acid availability.

Less data is available on the effect of dietary fibre on dietary mineral availability in cats. A study with adult cats fed diets enriched with cellulose (17\% dry matter) showed a positive relationship between increased faecal dry matter and calcium excretion, an increase in sodium and potassium excretion and higher water content in the faeces (Prola et al., 2009). In cats $10 \%$ sugar cane fibre addition to the diet induced higher faecal production, although to a lesser extent than with the same levels of cellulose supplementation ( 40.8 vs $45.3 \mathrm{~g}$ faeces 'as is' per cat per day, respectively). However, sugar cane supplementation did not alter faecal dry matter (Loureiro et al., 2017). Further research is needed to understand how sugar cane fibre may affect dietary mineral availability in cats.

The methods used bring new knowledge on the sugar cane fibre effect regarding the microstructure of cat feeding behaviour in the short term, and allows discrimination between products (Rogues and Niceron, 2015; Rogues et al., 2016). Further studies are warranted to understand the effect of long-term sugar cane fibre supplemented feeding durations on VFI. It would be useful to test this feeding strategy with higher $\mathrm{BCS}$ pets to observe any reduction in body weight.

\section{Conclusions}

Adding sugar cane fibre to the diet at a concentration of $7.3 \%$ or less in cat diets did not alter palatability. An inclusion of at least $5.5 \%$ of sugar cane fibre resulted in a significant decrease in cat VFI. A reduction of the maximum intake reached in one feeding event and a reduction in the number of feeding events were observed with sugar cane fibre inclusion at $7.3 \%$. Thus, the inclusion of sugar cane efficiently reduced VFI, without impairing the palatability performance of the product. Sugar cane fibre may therefore be a useful ingredient to add in feline diets targeting at weight loss and management programs. 


\section{Funding}

All research studies described were funded by Diana Petfood, a division of the Symrise group. All the products tested were developed by Diana Petfood. Sugar cane fibre used in this study is Fibre 3D from Vivae, Diana Pet Food.

\section{Availability of data and materials}

The datasets generated and analysed during the current study are not publicly available due to confidentiality but are available from the corresponding author on reasonable request.

\section{Conflict of interest}

The diets tested contained an ingredient provided by Vivae, a division of Diana Petfood. All but two of the authors (Julien Roguès, Anne Lepoudère, Delphine Lethuillier, Emira Mehinagic) are current employees of this company. Elodie Bouvret is a former employee of the company and was employed during the first versions of manuscript. The remaining author (Marta Hervera) is an employee of Expert Pet Nutrition and her advice and helps on this article was financially supported by Diana Petfood. All authors were involved in the writing of the manuscript and in the decision to submit the manuscript for publication.

\section{References}

Afnor, 1997. Animal feeding stuffs - Determination of sequential cell-wall - Method by treatment with neutral and acid detergent and sulfuric acid. Afnor publication NF V18-122. Afnor, Saint Denis, France.

Alexander, J.E., Colyer, A. and Morris, P.J., 2014. The effect of reducing dietary energy density via the addition of water to a dry diet, on body weight, energy intake and physical activity in adult neutered cats. Journal of Nutritional Science 3: e21. https:/doi.org/10.1017/ jns.2014.22

AOAC International, 1995. AOAC official methods of analysis. AOAC method 991.43. Total, soluble, and insoluble dietary fiber in foods. AOAC, Gaithersburg, MD, USA.

Bach, J.F., Rozanski, E.A., Bedenice, D., Chan, D.L., Freeman, L.M., Lofgren, J.L.S.; Oura, T.J. and Hoffman, A.M., 2007. Association of expiratory airway dysfunction with marked obesity in healthy adult dogs. American Journal of Veterinary Research 68: 670-675. https://doi.org/10.2460/ajvr.68.6.670

Beynen, A.C., Middelkoop, J. and Saris, D.H.J., 2011. Clinical signs of hairballs in cats fed a diet enriched with cellulose. American Journal of Animal and Veterinary Sciences 6(2): 69-72. https://doi. org/10.3844/ajavsp.2011.69.72

Butterwick, R.F. and Markwell, P.J., 1996. Changes in the body composition of cats during weight reduction by controlled dietary energy restriction. The Veterinary Record 138: 354-357. http:// dx.doi.org/10.1136/vr.138.15.354
Burrows, C.F. and Merritt, A.M., 1983. Influence of alpha-cellulose on myoelectric activity of proximal canine colon. American Journal of Physiology-Gastrointestinal and Liver Physiology 245: G301-G306. https://doi.org/10.1152/ajpgi.1983.245.2.G301

Cave, N.J., Allan, F.J., Schokkenbroek, S.L., Metekohy, C.A.M. and Pfeiffer, D.U., 2012. A cross-sectional study to compare changes in the prevalence and risk factors for feline obesity between 1993 and 2007 in New Zealand. Preventive Veterinary Medicine 107: 121-133. https://doi.org/10.1016/j.prevetmed.2012.05.006

Chandler, M., Cunningham, S., Lund, E.M., Khanna, C., Naramore, R., Patel, A. and Day, M.J., 2017. Obesity and associated comorbidities in people and companion animals: a one health perspective. Journal of Comparative Pathology 156: 296-309. https://doi.org/10.1016/j. jсра.2017.03.006

Cline, M., Witzel, A., Moyers, T., Bartges, J., Kirk, C., Cline, M., Witzel, A. and Claudia, K., 2012. Comparison of high fibre and low carbohydrate diets on owner-perceived satiety of cats during weight loss. American Journal of Animal and Veterinary Sciences.

Colliard, L., Paragon, B.M., Lemuet, B., Bénet, J.J. and Blanchard, G., 2009. Prevalence and risk factors of obesity in an urban population of healthy cats. Journal of Feline Medicine and Surgery 11: 135-140. https://doi.org/10.1016/j.jfms.2008.07.002

Corbee, R.J., 2014. Obesity in show cats. Journal of Animal Physiology and Animal Nutrition 98: 1075-1080. https://doi.org/10.1111/ jpn.12176

Courcier, E.A., Mellor, D.J., Pendlebury, E., Evans, C. and Yam, P.S., 2012. An investigation into the epidemiology of feline obesity in Great Britain: results of a cross-sectional study of 47 companion animal practises. Veterinary Record 171(22): 560. http://dx.doi. org/10.1136/vr.100953

Courcier, E.A., O'Higgins, R., Mellor, D.J. and Yam, P.S., 2010. Prevalence and risk factors for feline obesity in a first opinion practice in Glasgow, Scotland. Journal of Feline Medicine and Surgery 12: 746-753. https://doi.org/10.1016/j.jfms.2010.05.011

Day, J.E.L, Kyriazakis, I. and Rogers, P.J., 1998. Food choice and intake:towards a unifying framework of learning and feeding motivation. Nutrition Research Reviews: 11(1): 25-43. https://doi. org/10.1079/NRR19980004

De Godoy, M.R.C., Kerr, K.R. and Fahey Jr, G.C., 2013. Alternative dietary fiber sources in companion animal nutrition. Nutrients 5 : 3099-3117. https://doi.org/10.3390\%2Fnu5083099

Depauw, S., Hesta, M., Whitehouse-Tedd, K., Vanhaecke, L., Verbrugghe, A. and Janssens, G.P.J., 2013. Animal fibre: the forgotten nutrient in strict carnivores? First insights in the cheetah. Journal of Animal Physiology and Animal Nutrition 97(1): 146-154. https:// doi.org/10.1111/j.1439-0396.2011.01252.x

Dobenecker, B. and Kienzle, E., 1998. Interactions of cellulose content and diet composition with food intake and digestibility in dogs. The Journal of Nutrition 128: 2674S-2675S. https://doi.org/10.1093/ jn/128.12.2674S

Earle, K.E., Kienzle, E., Opitz, B., Smith, P.M. and Maskell, I.E., 1998. Fiber affects digestibility of organic matter and energy in pet foods. The Journal of Nutrition 128(12): 2798S-2800S. https:// doi.org/10.1093/jn/128.12.2798S 
Eastwood, M.A., Brydon, W.G. and Anderson, D.M., 1986. The effect of the polysaccharide composition and structure of dietary fibres on cecal fermentation and fecal excretion. The American Journal of Clinical Nutrition 44: 51-55. https://doi.org/10.1093/ajcn/44.1.51 European Commission (EC), 2009. Commission Regulation (EC) No 152/2009 of 27 January 2009 laying down the methods of sampling and analysis for the official control of feed. Official Journal of the European Union L 54: 1-130. Available at: https://eur-lex.europa. eu/eli/reg/2009/152/oj.

European Commission (EC), 2010. Directive 2010/63/EU of the European Parliament and of the Council of 22 September 2010 on the protection of animals used for scientific purposes. Official Journal of the European Union L 276: 33-79. Available at: http:// data.europa.eu/eli/dir/2010/63/oj.

Fekete, S., Hullar, I., Andrasofszky, E., Rigo, Z. and Berkenyi, T., 2001. Reduction of the energy density of cat foods by increasing their fibre content with a view to nutrients' digestibility. Journal of Animal Physiology and Animal Nutrition 85: 200-204. https://doi. org/10.1046/j.1439-0396.2001.00332.x

Fekete, S.G., Hullár, I., Andrásofszky, E. and Kelemen, F., 2004. Effect of different fibre types on the digestibility of nutrients in cats. Journal of Animal Physiology and Animal Nutrition 88(3-4): 138142. https://doi.org/10.1046/j.1439-0396.2003.00470.x

Fischer, M.M., Kessler, A.M., de Sá, L.R.M., Vasconcellos, R.S., Roberti Filho, F.O., Nogueira, S.P., Oliveira, M.C. and Carciofi, A.C., 2012. Fibre fermentability effects on energy and macronutrient digestibility, fecal traits, postprandial metabolite responses, and colon histology of overweight cats. Journal of Animal Science 90: 2233-2245. https://doi.org/10.2527/jas.2011-4334

German, A.J., 2006. The growing problem of obesity in dogs and cats. The Journal of Nutrition 136: 1940S-1946S. https://doi.org/10.1093/ jn/136.7.1940S

German, A.J., 2016. Weight management in obese pets: the tailoring concept and how it can improve results. Acta Veterinaria Scandinavica 58(1): 57. https://doi.org/10.1186/s13028-016-0238-z

German, A.J., Holden, S., Bissot, T., Morris, P.J. and Biourge, V., 2008. Changes in body composition during weight loss in obese client-owned cats: loss of lean tissue mass correlates with overall percentage of weight lost. Journal of Feline Medicine and Surgery 10: 452-459. https://doi.org/10.1016/j.jfms.2008.02.004

German, A.J., Holden, S.L., Bissot, T., Morris, P.J. and Biourge, V., 2010b. A high protein high fibre diet improves weight loss in obese dogs. The Veterinary Journal 183: 294-297. https://doi.org/10.1016/j. tvjl.2008.12.004

German, A.J., Ryan, V.H., German, A.C., Wood, I.S. and Trayhurn, P., 2010a. Obesity, its associated disorders and the role of inflammatory adipokines in companion animals. The Veterinary Journal 185: 4-9. https://doi.org/10.1016/j.tvjl.2010.04.004

Gerstein, D.E., Woodward-Lopez, G., Evans, A.E., Kelsey, K. and Drewnowski, A., 2004. Clarifying concepts about macronutrients? effects on satiation and satiety. Journal of the American Dietetic Association 104: 1151-1153. https://doi.org/10.1016/j. jada.2004.04.027
Hansen, W.E., 1986. Effect of dietary fibre on proteolytic pancreatic enzymes in vitro. International journal of pancreatology : official journal of the International Association of Pancreatology 1: 341351. https://doi.org/10.1007/bf02801866

Harper, E.J. and Siever-Kelly, C., 1997. The effect of fibre on nutrient availability in cats of different ages. Recent Advances in Animal Nutrition in Australia 110-116.

Hawthorne, A.J. and Butterwick, R.F., 1998. The satiating effect of a diet containing jojoba meal (Simmondsia chinensis) in dogs. The Journal of Nutrition 128: 2669S-2670S. https://doi.org/10.1093/ jn/128.12.2669S

Hours, M.A., Sagols, E., Junien-Castagna, A., Feugier, A., Moniot, D., Daniel, I., Biourge, V., Samuel, S., Queau, Y. and German, A.J., 2016. Comparison of voluntary food intake and palatability of commercial weight loss diets in healthy dogs and cats. BMC Veterinary Research 12: 274. https://dx.doi.org/10.1186\%2Fs12917-016-0899-x

Howarth, N.C., Saltzman, E. and Roberts, S.B., 2001. Dietary fibre and weight regulation. Nutrition Reviews 59: 129-139. https://doi. org/10.1111/j.1753-4887.2001.tb07001.x

Kane, E., Rogers, Q.R. and Morris, J.G., 1981. Feeding behavior of the cat fed laboratory and commercial diets. Nutrition Research 1(5): 499-507. https://doi.org/10.1016/S0271-5317(81)80053-X

Kay, R.M., 1982. Dietary fibre. Journal of Lipid Research 23: 221-242.

Kienzle, E., Meyer, H. and Schneider, R., 1991. Investigations on palatability, digestibility and tolerance of low digestible food components in cats. The Journal of Nutrition 121 (suppl_11): S56-S57. https://doi.org/10.1093/jn/121.suppl_11.s56

Kienzle, E., Schrag, I., Butterwick, R. and Opitz, B., 2001. Calculation of gross energy in pet foods: new data on heat combustion and fibre analysis in a selection of foods for dogs and cats. Journal of Animal Physiology and Animal Nutrition 85: 148-57. https://doi. org/10.1046/j.1439-0396.2001.00311.x

Kim, S.W., Morris, J.G. and Rogers, Q.R., 1995. Dietary soybean protein decreases plasma taurine in cats. Journal of Nutrition 125: 2831-7. https://doi.org/10.1093/jn/125.11.2831

Laflamme, D.P., 2012. Companion animals symposium: obesity in dogs and cats: What is wrong with being fat? Journal of Animal Science 90: 1653-1662. https://doi.org/10.2527/jas.2011-4571

Larose, C., Le Toux, M. and Guiller, I., 2007. Improved appetence measurement system. PCT WO 2007/107508 (A1), 27 September 2007. Available at: https://patentscope.wipo.int/search/en/detail. jsf?docId=WO2007107508.

Loureiro, B.A., Sakomura, N.K., Vasconcellos, R.S., Sembenelli, G., Gomes, M.O.S., Monti, M.E., Malheiros, B., Kawauchi, I.M. and Carciofi, A.C., 2017. Insoluble fibres, satiety and food intake in cats fed kibble diets. Journal of Animal Physiology and Animal Nutrition 101(5): 824-834. https://doi.org/10.1111/jpn.12468

Loureiro, B.A., Sembenelli, G., Maria, A.P.J., Vasconcellos, R.S., Sa, F.C., Sakomura, N.K. and Carciofi, A.C., 2014. Sugarcane fibre may prevent hairball formation in cats. Journal of Nutritional Science, Waltham Supplement 3: e20, 1-5. https://dx.doi. org/10.1017\%2Fjns.2014.27

Lund, E.M., Armstrong, P.J., Kirk, C.A. and Klausner, J.S., 2005. Prevalence and risk factors for obesity in adult cats from private US veterinary practices. International Journal of Applied Research in Veterinary Medicine 3(2): 88-96. 
McCrickerd, K. and Forde, C.G., 2016. Sensory influences on food intake control: moving beyond palatability. Obesity Reviews 17(1): 18-29. https://doi.org/10.1111/obr.12340

Mela, D.J., 2006. Eating for pleasure or just wanting to eat? Reconsidering sensory hedonic responses as a driver of obesity. Appetite 47(1): 10-17. https://doi.org/10.1016/j.appet.2006.02.006 Musco, N., 2014. Role of soluble and insoluble polysaccharides in omnivores and carnivores nutrition. PhD thesis, Università Degli Studi Di Napoli Federico II, Dipartimento Di Medicina Veterinaria E Produzioni Animali, Scuola di Dottorato in Produzione E Sanita Degli Alimenti Di Origine. Available at: http://www.fedoa.unina. it/9713/.

National Research Council (NRC), 1986. Nutrient requirements of cats. National Academy Press, Washington D.C., USA.

Prola, L., Dobenecker, B. and Kienzle, E., 2006. Interaction between dietary cellulose content and food intake in cats. The Journal of Nutrition 136: 1988S-1990S. https://doi.org/10.1093/jn/136.7.1759

Prola, L., Dobenecker, B., Mussa, P.P. and Kienzle, E., 2009. Influence of cellulose fibre length on faecal quality, mineral excretion and nutrient digestibility in cat. Journal of Animal Physiology and Animal Nutrition 94: 362-367. https://doi.org/10.1111/j.14390396.2008.00916.x

Prosky, L., Asp, N.G., Schweitzer T.F., DeVries J.W. and Furda I., 1992. Determination of insoluble and soluble and total dietary fibre in foods and food products: Interlaboratory study. Journal of the Association of Official Analytical Chemists International 75: 360-367.

Rogues, J. and Niceron, C., 2015. Method for selecting petfoods having a palatability effect and a calorie intake reducing effect for pets. PCT WO 2015/155177 (A1), 15 October 2015. Available at: https:// patentscope.wipo.int/search/en/detail.jsf?docId=WO2015155177.

Rogues, J., Le Paih, L., Forges, C., Niceron, C. and Mehinagic, E., 2016. Kinetics of consumption, an innovative tool to measure cat food palatability and satiety palatability and satiety. Proceedings of the $14^{\text {th }}$ Symposium on Statistical Methods for the Food Industry. Available at: http://agrostat2016.sfds.asso.fr/wp-content/ uploads/2016/03/3.P1_J.Rogues.pdf.

Rowe, E., Browne, W., Casey, R., Gruffydd-Jones, T. and Murray, J., 2015. Risk factors identified for owner-reported feline obesity at around one year of age: dry diet and indoor lifestyle. Preventive Veterinary Medicine 121: 273-281. https://doi.org/10.1016/j. prevetmed.2015.07.011

Schwartz, M.W., Woods, S.C., Porte, D., Seelay, R.J. and Baskin, D.J., 2000. Central nervous system control food intake. Nature 404: 661-671. https://doi.org/10.1038/35007534

Serisier, S., Pizzagalli, A., Leclerc, L., Feugier, A., Nguyen, P., Biourge, V. and German, A.J., 2014. Increasing volume of food by incorporating air reduces energy intake. Journal of Nutritional Science 3: e59. https://dx.doi.org/10.1017\%2Fjns.2014.43
Stock-Damgé, C., Bouchet, P., Dentinger, A., Aprahamian, M. and Grenier, J.F., 1983. Effect of dietary fiber supplementation on the secretory function of the exocrine pancreas in the dog. American Journal of Clinical Nutrition 38: 843-848. https://doi.org/10.1093/ ajcn/38.6.843

Stratton-Phelps, M., Backus, R.C., Rogers, Q.R. and Fascetti, A.J., 2002. Dietary rice bran decreases plasma and whole-blood taurine in cats. Journal of Nutrition 132: 1745S-7S. https://doi.org/10.1093/ jn/132.6.1745S

Tarkosova, D., Story, M.M., Rand, J.S. and Svoboda, M., 2016. Feline obesity - prevalence, risk factors, pathogenesis, associated conditions and assessment: a review. Veterinarni Medicina 61(6): 295-307. https://doi.org/10.17221/145/2015-VETMED

The European Pet Food Industry Federation (FEDIAF), 2019. Nutritional guidelines for complete and complementary pet food for cats and dogs. Available at: http://www.fediaf.org/self-regulation/ nutrition.html.

Tobie, C., Péron, F. and Larose, C.; 2015. Assessing food preferences in dogs and cats: a review of the current methods. Animals 5(1): 126-137. https://dx.doi.org/10.3390\%2Fani5010126

Tukey, J.W., 1949. Comparing individual means in the analysis of variance. Biometrics 5(2): 99-114. JSTOR, www.jstor.org/ stable/3001913.

Tvarijonaviciute, A., Ceron, J.J., Holden, S.L., Morris, P.J., Biourge, V. and German, A.J., 2012. Effects of weight loss in obese cats on biochemical analytes related to inflammation and glucose homeostasis. Domestic Animal Endocrinology 42: 129-141. https:// doi.org/10.1016/j.domaniend.2011.10.003

Van Avesaat, M., Troost, F.J., Ripken, D., Hendriks, H.F. and Masclee, A.A.M., 2015. Ileal brake activation: macronutrient-specific effects on eating behaviour? International Journal of Obesity 39: 235-243. https://doi.org/10.1038/ijo.2014.112

Veloso, R.R., Sakomura, N.K., Kawauchi, I.M., Malheiros, E.B. and Carciofi, A.C., 2014. Effects of food processing and fibre content on the digestibility, energy intake and biochemical parameters of Blue-and-gold macaws (Ara ararauna L. - Aves, Psittacidae). Journal of Animal Physiology and Animal Nutrition 98: 251-261. https://doi.org/10.1111/jpn.12075

Verbrugghe, A. and Hesta, M, 2017. Cats and carbohydrates: the carnivore fantasy? Veterinary Sciences 4(4): 55. https://doi. org/10.3390/vetsci4040055

Vinik, A.I. and Jenkins, D.J., 1988. Dietary fiber in management of diabetes. Diabetes Care 11: 160-173. https://doi.org/10.2337/ diacare.11.2.160

Wang, Z.Q., Yu, Y., Zhang, X.H., Floyd, Z.E., Boudreau, A., Lian, K. and Cefalu, W.T., 2012. Comparing the effects of nano-sized sugar cane fibre with cellulose and psyllium on hepatic cellular signaling in mice. International Journal of Nanomedicine 7: 2999-3012.

Weber, M., Bissot, T., Servet, E., Sergheraert, R., Biourge, V.C. and German, A.J., 2007. A high-protein, high-fibre diet designed for weight loss improves satiety in dogs. Journal of Veterinary Internal Medicine 21: 1203-1208. https://doi.org/10.1892/07-016.1 
